\title{
O COREDE ALTO JACUÍ NO CONTEXTO DA PNDR/CNDR: REFLEXÕES SOBRE A QUESTÃO MIGRATÓRIA
}

\author{
THE COREDE ALTO JACUÍ IN THE CONTEXT OF \\ PNDR/CNDR: SOME REFLECTIONS ON THE MIGRATION \\ ISSUE
}

José Carlos Severo Corrêa

Universidade Federal do Pampa/Campus Itaqui - Itaqui - RS - Brasil

Rogério Leandro Lima da Silveira

Universidade de Santa Cruz do Sul - Santa Cruz do Sul - RS - Brasil

Grazielle Betina Brandt

Universidade de Santa Cruz do Sul - Santa Cruz do Sul - RS - Brasil

\begin{abstract}
Resumo: O presente trabalho tem como objetivo estabelecer uma discussão sobre a utilização de alguns dos indicadores tradicionais como critérios de elegibilidade para beneficiários de políticas públicas, no caso, a Política Nacional de Desenvolvimento Regional-PNDR, e a dinâmica de desenvolvimento da região do Conselho Regional de Desenvolvimento-COREDE Alto Jacuí, no Rio Grande do Sul. Através de um olhar sobre informações econômicas e demográficas da região, a reflexão parte da proposta apresentada pelos Coredes na Conferência Nacional de Desenvolvimento Regional-CNDR e que prevê a utilização dos fluxos migratórios como um dos critérios de elegibilidade para a nova PNDR. Tal reflexão foi baseada em análise conjunta de informações econômicas e demográficas para os períodos censitários de 2000 e 2010, da contagem populacional de 2007 e de informações relacionadas com o comportamento da economia da região. Procurou-se evidenciar que a dinâmica econômica é uma variável importante a ser considerada na análise dos fluxos migratórios regionais em um contexto de discussão que se estabelece a partir da PNDR. No entanto, para que o fenômeno seja tratado de forma abrangente, é relevante incluir, para além da perspectiva econômica, variáveis que perpassam os sentidos do movimento migratório.
\end{abstract}

Palavras Chave: Corede Alto Jacuí. PNDR. CNDR. Economia regional. Fluxos migratórios.

\begin{abstract}
His study aimed to establish a discussion between the use of some of the traditional indicators such as eligibility criteria for beneficiaries of public policies, in this case, the National Policy For Regional Development (PNDR) and the dynamics of development on the area covered by the Regional Development Council (COREDE) Alto Jacuí, in Rio Grande do Sul. Through a look at economic and demographic information, this study provides a counterpoint to the proposal submitted by the Coredes in the National Conference of Regional Development (CNDR), which stipulated the use of the migration flows as one of the eligibility criteria for the new PNDR. This reflection was based on an analysis of information from censuses of years 2000 and 2010 and the population counting 2007 with information related to the performance of the regional economy. We tried to show that the economic dynamics exerts a strong impact on regional migratory flows in the context from the PNDR. However, it is relevant to include other variables such as the meaning of the migratory phenomenon as they are closely interrelated.
\end{abstract}

Keywords: Corede Alto Jacuí. PNDR. CNDR. Regional economy. Migration. 


\section{INTRODUÇÃO}

O presente trabalho estabelece uma reflexão em torno dos movimentos migratórios a e a política nacional de desenvolvimento regional. Nesse sentido, tendo como ponto de partida a PNDR e a discussão realizada na primeira CNDR, a reflexão proposta se dá a partir de uma região específica. No caso, a região selecionada para análise é a de abrangência do Corede Alto Jacuí, localizada na porção centro norte do Rio Grande do Sul, e composta por 14 municípios: Boa Vista do Cadeado, Boa Vista do Incra, Colorado, Cruz Alta, Fortaleza dos Valos, Ibirubá, Lagoa dos Três Cantos, Não Me Toque, Quinze de Novembro, Saldanha Marinho, Salto do Jacuí, Santa Bárbara do Sul, Selbach e Tapera.

Sem a intenção de esgotar o assunto, a ideia é compreender melhor a interação que se estabelece entre a concepção da política pública estudada e a compreensão das dinâmicas de desenvolvimento recentes na região. Dessa forma, estabelece-se uma discussão que priorize a utilização de alguns dos indicadores tradicionais ${ }^{1}$ como critérios de elegibilidade para beneficiários de políticas públicas, no caso a PNDR, ao relacioná-las com algumas dinâmicas territoriais de desenvolvimento recentes na região. Ainda, a discussão está centrada em uma crítica feita aos critérios previamente estabelecidos no âmbito do documento base da PNDR, enfatizados pela perspectiva econômica e de seu contraponto focado nas questões demográficas e migratórias.

O texto está organizado em três seções, para além dessa introdução. $\mathrm{Na}$ próxima seção serão apresentadas algumas contextualizações em torno da PNDR, bem como da CNDR. Na sequência se estabelece, a partir da região de análise, uma reflexão de alguns indicadores que se propõe a refletir sobre aspectos que passaram a ser referenciados na CNDR, especialmente relacionados à dinâmica econômica e os fluxos migratórios. Busca-se, a partir dessa ótica, correlacionar os movimentos migratórios com o comportamento da economia da região. Tal reflexão não explica plenamente e tampouco elimina outras possibilidades em termos de análise e interpretações. E, por fim, são apresentadas considerações provisórias, vislumbrando a necessidade de aprofundamentos de temáticas que (re)pensem as migrações, as questões econômicas e as políticas públicas em torno do desenvolvimento regional.

\section{CONTEXTUALIZAÇÕES EM TORNO DA CNDR / PNDR: O PLANEJAMENTO E A QUESTÃO MIGRATÓRIA}

Durante a realização da primeira CNDR, realizada pelo Ministério da Integração Nacional-MI em 2012, várias foram as discussões em pauta. No documento base, chamou-se a atenção para a questão dos desequilíbrios regionais, sendo qualificados como nefastos à economia e à sociedade brasileira e no qual, segundo o MI (2012), é possível destacar a falta de oportunidades aos

\footnotetext{
1 Especificamente neste texto, os critérios de elegibilidade que estão sendo chamados de tradicionais, são os indicadores consagrados na economia, como é o caso da renda média e variação do Produto Interno Bruto (PIB). (MI, 2012a; 2012b; BANDEIRA, 2012)
} 
que nascem em regiões menos favorecidas, a movimentação populacional em favor das regiões metropolitanas e o sub-aproveitamento do potencial produtivo do país. Sendo que,

superar este quadro é uma exigência do momento, trata-se do enfrentamento de uma dívida histórica que não pode mais ser adiada. Seu enfrentamento, entretanto, supõe a construção de um amplo consenso político e federativo e depende de escolhas urgentes e corajosas. (MI, 2012, p.5).

A realização da conferência traz também, em seu escopo, a intenção, por parte do governo federal, na transformação da PNDR em política de Estado, condição não obtida pela sua primeira versão, ainda percebida como uma política de governo. A PNDR estaria, então, dividida em dois momentos, o primeiro em vigência e o segundo a partir da transformação da mesma em política de Estado após a aprovação da lei resultante da conferência (MI, 2010, 2012).

Nesse sentido, é importante ressaltar que a primeira versão da política, ainda vigente, tem sido alvo de muitas críticas $^{2}$ em vários pontos, tanto na forma quanto no conteúdo, e nas mais diversas esferas. No entanto, há que se ressaltar que a realização da conferência dá um novo alento quanto a sua efetiva aplicabilidade, pois o próprio formato de conferência pressupõe que haja, nesse momento, uma maior preocupação governamental com a sua efetivação.

É justamente a partir das críticas à primeira versão da PNDR e ao texto base da CNDR que se alicerça a construção proposta neste trabalho, que remete a um olhar sobre os critérios estabelecidos para a implementação da política, a partir de circunstâncias que contextualizam noções sobre planejamento para o desenvolvimento e a questão migratória.

Quanto a sua forma, a PNDR foi apresentada em 2003 e institucionalizada pelo Decreto 6.047, de 22 de fevereiro de 2007 (MI, 2010), trazendo em seu contexto uma análise multivariada. Dessa forma,

isoladamente, nem os aspectos econômicos nem os políticos são suficientes para explicá-la ou mitigá-la, sendo essa, ao mesmo tempo, uma questão econômica e política. Isso pode ser visto na maneira pela qual os processos de integração físico-territorial e de integração econômica foram conduzidos no país ao longo de sua história recente. (MI, 2010, p.11).

Embora, em seu texto, a PNDR afirme que o foco da política é superar a questão das escalas de homogeneidade, ao definir os critérios de elegibilidade tomando por base a renda média por domicílio e o Produto Interno Bruto-PIB

\footnotetext{
${ }^{2}$ Bandeira (2012) apresenta uma série de questões que não foram tratadas com a devida objetividade no documento ou nas discussões realizadas até então..., como é o caso da constituição do Fundo Nacional de Desenvolvimento Regional e a consequente centralização dos recursos constitucionais nas regiões direcionadas exclusivamente às macrorregiões Norte, Nordeste e Centro-Oeste e cujo foco é o financiamento de empresas, acarretando uma dependência de recursos orçamentários para viabilizar a política regional. Além disso, a perda de importância da política na agenda governamental é outro fato criticado, que em boa medida é explicado pelo relativo sucesso das políticas sociais de transferência de renda e da interpretação de que a política regional é uma política social territorializada.
} 
percapita, sua base de enfrentamento praticamente reafirma a ideia de que o foco estabelecido, em âmbito nacional, seja prioritariamente voltado às regiões Norte, Nordeste e Centro-Oeste, como já mencionado anteriormente.

Já a CNDR traz em seu texto de referência algumas críticas à primeira versão da PNDR, como é o caso do processo de planejamento ${ }^{3}$ centralizado, de cima para baixo, adotado no modelo anterior, bem como a falta de articulação intragovernamental em torno de suas mais diversas propostas, dentre outras. Como decorrência dessa auto avaliação para a CNDR a proposição original foi a de criação de espaços sub-regionais de planejamento, nos moldes dos Coredes do Rio Grande do Sul, e também a ampliação do espectro de abrangência das chamadas Regiões Programas (MI, 2012). De certa forma, naquele período, a proposta ainda permanecia muito restritiva, pois o foco continuava na variável renda e, consequentemente, a referência permanecia concentrada na questão do valor per capita, o que resultou em manifestações contrárias advindas dos Coredes.

Bandeira (2012), ao apresentar a contribuição dos Coredes à política, mencionou que o critério PIB per capita, variável que explicita a dinâmica da economia de uma região, de acordo com a proposta original, estaria sujeito a questões circunstanciais ${ }^{4}$ e que poderiam distorcer a realidade de uma região qualquer. Nessa perspectiva, Bandeira (2012) observa que:

com base nas variáveis renda e crescimento do PIB, só seriam possíveis comparações inter-regionais suficientemente seguras para definir tratamento diferenciado no acesso a recursos caso fosse possível tomar como base para o cálculo períodos "típicos", em que a influência de fatores aleatórios não fosse significativa. Circunstâncias muito favoráveis ou muito desfavoráveis, como safras excepcionais, secas, chuvas em excesso, incidência de pragas, preços muito altos ou muito baixos, etc., podem causar distorções importantes, fazendo com que a classificação de algumas regiões possa variar - entre pobres e ricas, ou entre dinâmicas e estagnadas - devido apenas à escolha de um ou outro ano ou período de referência. Quando se considera um país com a extensão territorial e com a diversidade geográfica do Brasil, chega-se a conclusão que não será possível encontrar anos ou períodos que sejam "típicos" para todas as regiões. Parece inevitável que qualquer ano ou período que possa ser escolhido acabará sendo "típico" para algumas e "atípico" para outras. (BANDEIRA, 2012, p.11).

Além disso, o autor menciona o fluxo migratório negativo de algumas regiões que, pelo critério previamente estabelecido na PNDR, poderiam ser classificadas como dinâmicas ou desenvolvidas, sugerindo, então, a adoção de outros critérios, mesmo que percebidos de forma complementar. Ao atentar para a questão dos fluxos migratórios, Bandeira (2012) evidencia que uma região dinâmica oferece oportunidades de trabalho a seus habitantes, sendo, portanto,

\footnotetext{
${ }^{3}$ Villaça (2000) faz uma crítica veemente ao uso indiscriminado das expressões plano e planejamento, as quais de acordo com sua percepção representam em boa medida apenas figura de retórica, sendo vistos como peça de ficção, elaborados academicamente, sem a conexão com a realidade não atacando o problema, havendo também um descolamento entre a tecnocracia, que elabora os planos e a política, que deveria implementá-los e os ignora solenemente.

${ }^{4}$ Tais circunstâncias, preliminarmente mencionadas por Bandeira (2012), deverão ser discutidas de forma mais aprofundada na próxima seção.
} 
desnecessário a emigração. Ainda na perspectiva de Bandeira (2012, p.203), "a utilização da dinâmica demográfica para identificar 'regiões problema' não constitui ideia nova, pois a literatura registra que a emigração com frequência é utilizada na definição da elegibilidade para ações de políticas regionais." ${ }^{5}$

Como resultado dessa ponderação, logrou êxito a ideia sustentada por Bandeira e defendida pelos representantes do Rio Grande do Sul nas etapas macrorregional e nacional da CNDR, compostas, em bom número, por representantes dos Coredes. Essa se constituiu em uma vitória parcial, à medida que o objetivo principal ainda é focado nas regiões Norte e Nordeste. No entanto, ao se estabelecer como objetivo segundo da CNDR um critério que leva em consideração o fluxo migratório, pode-se salientar que houve um avanço ${ }^{6}$.

A argumentação relacionada ao movimento populacional foi utilizada em crítica ao critério baseado especificamente nos indicadores econômicos. Contudo, tanto a questão demográfica quanto econômica coadunam na base da argumentação do $\mathrm{MI}$ ao contextualizar a discussão em torno da PNDR.

1) Os cidadãos brasileiros são punidos por seu local de nascimento. Aqueles que nascem nas regiões menos dinâmicas terão suas chances de crescimento pessoal e profissional profundamente limitadas em razão do baixo acesso à educação, à saúde, ao emprego de qualidade e a toda uma gama de serviços e oportunidades.

2) A desigualdade induz uma movimentação populacional em direção aos espaços mais dinâmicos, agravando o fenômeno da megametropolização com todas as suas consequências de favelização, pobreza e violência bastante conhecidas. (MI, 2012, p.5).

Ao ponderar que a superação dessa situação é uma exigência imposta pelo atual momento e que marca o potencial de desenvolvimento de muitas regiões, o texto da reformulação da PNDR reconhece ainda que "a PNDR teria abrangência nacional, em múltiplas escalas geográficas, já que as desigualdades regionais no Brasil se manifestavam não apenas entre as macrorregiões, mas também intrarregionalmente em todo o território" (Ml, 2012, p.10).

No entanto, ao estabelecer critérios de elegibilidade que atente para a questão migratória, o texto de reformulação sinaliza apenas com aspectos puramente econômicos, como renda média domiciliar e variação do PIB. Entre outras questões ${ }^{7}$, essa foi a grande crítica feita ao texto base proposto pelo MI. Em outros termos, o texto menciona a importância da questão migratória como fenômeno capaz de intensificar as desigualdades regionais, mas não estabelece o

\footnotetext{
${ }^{5}$ Elevada emigração a partir de uma área é frequentemente considerada sintoma de um problema regional e, portanto, como indicador de elegibilidade para uma intervenção de política pública com o objetivo de promover o desenvolvimento territorial. (OECD, 2001, apud BANDEIRA, 2012, p.203)

${ }^{6}$ Importante mencionar que o projeto de reformulação da PNDR tem uma longa trajetória a cumprir no Congresso Nacional, cuja função é discutir e aprovar a nova Lei, que passaria a vigorar com a Sanção da Presidência da República. Depois há ainda a necessidade de viabilizar efetivamente sua implementação, principalmente com a financeirização dos fundos previstos.

${ }^{7}$ No texto de Bandeira (2012) são apresentadas outras críticas, mas que em decorrência do escopo deste trabalho não serão aqui discutidas, restringindo-se, portanto a reflexão em torno da migração.
} 
mesmo como critério de elegibilidade, como se o enfrentamento de tal situação fosse facilmente equalizado de forma indireta.

Nesse aspecto, a argumentação principal é a de que, embora não exclusivamente por isto, determinados eventos que afetam a renda gerada explicam o fluxo migratório negativo entre os censos de 2000 e 2010. Tal fato demonstra que as questões econômicas impactam para melhor ou para pior na questão populacional e, especificamente, nesse caso, o que se observa é que a diminuição da população tende a ocultar os efeitos dos problemas estruturais da economia regional. O Alto Jacuí é considerado pelos critérios da PNDR como região de alta renda e, portanto, inelegível como região prioritária da política. Entretanto, em função das características da estrutura econômica da região, verifica-se que tem comportamento semelhante ao de regiões classificadas como prioritárias. Dessa forma, ao visualizar o argumento de Bandeira (2012) permite-se a possibilidade de refletir que outras regiões também possam ser beneficiadas pela PNDR.

\section{O COREDE ALTO JACUÍ E SUAS CONEXÕES COM A CNDR/PNDR: PERSPECTIVAS DEMOGRÁFICAS E ECONÔMICAS}

$\mathrm{Na}$ seção anterior foi apresentado o contexto e os desdobramentos em torno das discussões sobre a questão migratória na CNDR e PNDR e, de modo geral, no que diz respeito ao Corede Alto Jacuí. Essa foi uma significativa mudança na construção da política, pois pelo primeiro critério ${ }^{8}$ não seria este contemplado como área prioritária. Contudo, a partir da revisão, o mesmo passou a ser considerado como região elegível.

Assim, como pode ser percebido no Projeto de Lei da PNDR, essa condição ficaria garantida se aprovada a lei pelo Congresso Nacional.
(...) Art. $2^{\circ}(\ldots)$
II - garantir a competitividade regional e a geração de emprego e renda em regiões que apresentam declínio populacional e elevadas taxas de emigração;
(...)
Art. $9^{\circ}$ - Em relação ao objetivo constante do inciso II do art. $2^{\circ}$, são elegíveis as $\mathrm{MRGs}^{9}$ que apresentaram crescimento populacional negativo e aquelas que cresceram a taxas inferiores a $50 \%$ da média nacional, medidos pela Taxa de Crescimento Populacional da MRG em relação à média nacional do último Censo Demográfico do IBGE. ${ }^{10}$

No caso específico da região de abrangência do Corede Alto Jacuí, verificase entre os censos de 2000 e 2010, uma redução na população na ordem de $3,1 \%$, equivalente a 4.967 habitantes. No censo de 2000, eram 160.231

\footnotetext{
${ }^{8}$ Já na primeira versão da PNDR, o Alto Jacuí não foi considerado como região contemplável, pois os critérios de renda média e variação do PIB, justamente pelas questões mencionadas por Bandeira (2012), o resultado da safra de 2003 foi muito bom, e esse foi o ano de apresentação da PNDR, fato que se repete nos anos que precederam a preparação da CNDR. Essas condições asseguraram ao Alto Jacuí nesses anos boa variação do PIB e também aumento da renda média.

${ }^{9}$ Microrregiões.

${ }^{10}$ Instituto Brasileiro de Geografia e Estatística.
} 
habitantes na região, sendo que, no censo de 2010, este número foi reduzido a 155.264 habitantes. Ao realizar uma avaliação entre os períodos censitários de 2000 e 2010, tem-se os dados apresentados de forma bruta. No entanto, em análise mais apurada, considerando-se os dados da contagem populacional de 2007, constata-se uma situação ligeiramente distinta, delimitando-se, assim, um marco divisor ou ponto de inflexão, pois a redução de população em um período de sete anos, entre 2000 e 2007, foi de 5.877 habitantes, o que equivale a 3,67\% do total.

Observa-se, portanto, que a perda efetiva da população se deu até o ano de $2007^{11}$, ano da contagem populacional. Entre 2007 e o censo de 2010 houve, inclusive, recuperação da população com a agregação de 910 novos habitantes ou um número 0,6\% superior de habitantes na região.

Em comparação ao estado, a região do Alto Jacuí apresenta comportamento inverso, pois, enquanto nessa região a população diminuiu, no estado ela aumentou, tanto na contagem populacional de 2007 quanto no censo de 2010, sendo estes relacionados ao censo de 2000. Entre 2000 e 2007, a população do estado aumentou em 387.465 habitantes, equivalente a $3,8 \%$ de aumento populacional. Já no censo de 2010 o aumento foi de 4,97\%, ou seja, mais de 506.131 habitantes. De 2007 para 2010, o aumento foi de 1,12\% na população, ou a agregação de 118.666 novos habitantes. Como observado anteriormente, a região do Alto Jacuí teve comportamento distinto, mesmo quando inverteu a tendência. O que se observa é que há no Estado do Rio Grande do Sul um aumento vegetativo da população, embora a uma taxa pequena, mas consistente, haja vista que a tendência histórica tem sido de redução dessa taxa ${ }^{12}$, enquanto, na região do Alto do Jacuí, a tendência é inversa.

Ainda, em termos regionais, se eventualmente a população do Alto do Jacuí tivesse se mantido estável, pode-se, então, sugerir, para esse período, uma determinada estagnação, tendo em vista que denota o envelhecimento da população em função de seu baixo crescimento vegetativo, o que no caso é agravado pela sua diminuição. Não obstante, há um dado instigante a ser observado, pois a redução da população se deu fundamentalmente até 2007, não significando e não sendo possível mensurar, por exemplo, que foi de 2006 para 2007 que tenha ocorrido essa diminuição ou se foi um fenômeno gradual ano a ano. Mas, independente de como se comportou a movimentação populacional, se abrupta ou suavemente, o comportamento econômico da região explica em medida tal fenômeno, considerando que a região é fortemente dependente do agronegócio, sobretudo da cultura da soja.

Esse mercado, na primeira metade da década de 2000, esteve bastante oscilante em função da conjuntura econômica do país, marcada pelo descontrole da taxa de câmbio em função dos ataques especulativos pelo mercado financeiro à moeda nacional, o real. (FEE, 2014; ZYLBERSZTAJN, 2005)

\footnotetext{
${ }^{11}$ Ressalta-se a importância da realização da contagem populacional em períodos intermediários como forma de acompanhar mais efetivamente os fenômenos populacionais.

${ }^{12}$ Embora não sendo o foco da discussão, é importante pontuar que ao se analisar os últimos censos, verifica-se que o aumento da população tem se dado a taxas decrescentes. No Estado, em 1980 a variação foi de $16,64 \%$, em 1991 variou $17,56 \%$ e em $2000,11,48 \%$, sempre em relação ao censo anterior.
} 
Essa é justamente a base da argumentação de Bandeira (2012), ao ponderar que, em parte, a dinâmica econômica da região é responsável pelo aumento ou diminuição da população, seja naturalmente (crescimento vegetativo) ou por força da migração. O autor, em seu texto, elenca questões pontuais ou atípicas que podem interferir no desempenho da economia, como, por exemplo, um ano de seca e consequente frustração de safra ou, ao contrário, de chuvas abundantes e bem distribuídas com uma supersafra. É com base nesse raciocínio que se pretende demonstrar que as variáveis econômicas, mesmo que não sejam indicadores exclusivos, de alguma forma influenciam no contexto geral da região e, consequentemente, na migração. Ao observar a tabela 1, que traz dados relacionados à população na região do Corede Alto Jacuí e do Estado do Rio Grande do Sul, pode-se fazer uma breve reflexão em torno da questão migratória.

Tabela 1. População do Alto Jacuí para os censos (2000 e 2010) e a contagem populacional (2007) e variação percentual entre os respectivos períodos ${ }^{13}$

\begin{tabular}{|c|c|c|c|c|c|c|}
\hline Município & 2000 & 2007 & 2010 & $\% \quad 07 / 00$ & $\% 10 / 00$ & $\% 10 / 07$ \\
\hline Boa Vista do Cadeado & 2471 & 2439 & 2441 & $-1,30 \%$ & $-1,21 \%$ & $0,08 \%$ \\
\hline Boa Vista do Incra & 2282 & 2403 & 2425 & $5,30 \%$ & $6,27 \%$ & $0,92 \%$ \\
\hline Colorado & 4072 & 3725 & 3550 & $-8,52 \%$ & $-12,82 \%$ & $-4,70 \%$ \\
\hline Cruz Alta & 67350 & 63119 & 62821 & $-6,28 \%$ & $-6,72 \%$ & $-0,47 \%$ \\
\hline Fortaleza dos Valos & 5079 & 4554 & 4575 & $-10,34 \%$ & $-9,92 \%$ & $0,46 \%$ \\
\hline Ibirubá & 18633 & 18604 & 19310 & $-0,16 \%$ & $3,63 \%$ & $3,79 \%$ \\
\hline Lagoa dos Três Cantos & 1627 & 1587 & 1598 & $-2,46 \%$ & $-1,78 \%$ & $0,69 \%$ \\
\hline Não-Me-Toque & 14413 & 15143 & 15936 & $5,06 \%$ & $10,57 \%$ & $5,24 \%$ \\
\hline Quinze de Novembro & 3582 & 3547 & 3653 & $-0,98 \%$ & $1,98 \%$ & $2,99 \%$ \\
\hline Saldanha Marinho & 3195 & 2970 & 2869 & $-7,04 \%$ & $-10,20 \%$ & $-3,40 \%$ \\
\hline Salto do Jacuí & 12948 & 12059 & 11880 & $-6,87 \%$ & $-8,25 \%$ & $-1,48 \%$ \\
\hline Santa Bárbara do Sul & 10003 & 9054 & 8829 & $-9,49 \%$ & $-11,74 \%$ & $-2,49 \%$ \\
\hline Selbach & 4861 & 4755 & 4929 & $-2,18 \%$ & $1,40 \%$ & $3,66 \%$ \\
\hline Tapera & 10564 & 10395 & 10448 & $-1,60 \%$ & $-1,10 \%$ & $0,51 \%$ \\
\hline Corede Alto Jacuí & 160231 & 154354 & 155.264 & $-3,67 \%$ & $-3,10 \%$ & $0,59 \%$ \\
\hline Rio Grande do Sul & 10187798 & 10575263 & 10693929 & $3,80 \%$ & $4,97 \%$ & $1,12 \%$ \\
\hline
\end{tabular}

Fonte: FEE, 2014.

Como já mencionado, houve, na região do Corede Alto Jacuí, entre os censos, uma redução da população, mas, efetivamente, o que explica tal comportamento ou quais seriam as causas desse fenômeno carece de aprofundamentos, tendo em vista que, no caso do estado, há outro comportamento. Conforme sinalizado anteriormente, procura-se, na economia da região, algumas explicações. Dessa forma, foi estabelecido um cruzamento dos dados relativos ao PIB nominal entre os anos de 2000 e 2010, com as projeções populacionais feitas para o mesmo período, no qual se encontrou um coeficiente

\footnotetext{
${ }^{13}$ No censo de 2000, Boa Vista do Cadeado ainda era município de Cruz Alta e Boa Vista do Incra estava dividida entre Cruz Alta e Fortaleza dos Valos, municípios estes que Ihes deram origem. Nesse sentido, a população dos dois municípios novos estava computada como dos municípios originários, logo a população apresentada na tabela foi constituída com base em estimativa projetada conforme a localização projetada dos questionários respondidos. Ou seja, a estimativa levou em consideração que a resposta questionário estando no território atualmente compreendido pelos novos municípios passou a considerar a população do mesmo, o que não é certeza de que tenha se confirmado, prejudicando, assim, as comparações específicas a esses municípios.
} 
de correlação de 0,96, ou seja, com $96 \%$ de explicação na relação entre as variáveis. Tal comportamento, evidenciado a partir de cálculos estatísticos, pode ser melhor visualizado no gráfico abaixo.

Com relação ao gráfico 1, ainda são pertinentes alguns comentários. Entre eles, destaca-se uma primeira observação em torno da importância da contagem populacional nos estudos demográficos, pois é em função da mesma que se possibilita uma análise como a proposta neste estudo. Já no que diz respeito ao PIB, o mesmo foi deflacionado com base no ano 2000, isto é, cada ano foi defasado de acordo com o Índice de Preços ao Consumidor Amplo-IPCA calculado pelo IBGE, de tal forma que a variação do mesmo é apresentada em termos reais. O PIB apresentou três movimentos distintos no período, uma tendência de elevação até 2003, com redução até 2005 , e uma retomada do crescimento a partir de então. E no caso da população são apresentadas duas informações: uma sendo a estimativa populacional apurada pela Fundação de Economia e EstatísticaFEE, com base numa tendência apurada em função dos dados reais nos pontos extremos, evidenciando uma queda sistemática da população em taxas uniformes; a outra informação é a população apurada efetivamente pelo Instituto Brasileiro de Geografia e Estatística-IBGE, fruto dos censos ou da contagem populacional, na qual é possível identificar o comportamento diferenciado e desuniforme entre censos.

Como já mencionado, a redução da população no Alto Jacuí ocorreu, principalmente, entre o censo de 2000 e contagem populacional de 2007, mas fica a questão: Quais as causas disso? O gráfico 1 aponta algumas evidências, sendo a queda drástica do PIB um indicativo. No entanto, surge uma outra questão: quais as causas da queda do mesmo neste período? Que conexão teria isso com o argumento inicial de que os critérios de elegibilidade propostos na PNDR, vinculados ao PIB e à renda percapita, seriam insuficientes?

Ao buscar evidências que possam sustentar ou auxiliar na explicação, identifica-se dois grandes eventos que aconteceram durante o período: a queda brusca do preço da soja na safra 2003/04 e a grande seca que assolou a safra 2004/05, sendo que a ocorrência desses dois eventos oferece algumas possíveis explicações.

A queda do preço da soja na safra de 2003/04, que, entre extremos, chegou a assinalar uma redução de $33 \%$ no preço médio do grão é devida a, pelo menos, três fatos. O primeiro marca uma quebra na tendência de elevação do preço do grão no mercado mundial por conta da elevação de seus estoques, que passaram de 1,633 milhões de toneladas em 2003 para 2,332 milhões de toneladas em 2004, sobretudo por boas safras nos Estados Unidos (AGRIANUAL, 2010).

O segundo remete à conjuntura econômica do país, com descontrole da taxa de câmbio em função dos ataques especulativos pelo mercado financeiro à moeda nacional, o real (FEE, 2014).

Já o terceiro é uma particularidade brasileira, o evento conhecido como 'soja da China', que, segundo Zylbersztajn (2005, p. 121-2)

(...) surpreenderam algumas partidas de soja exportadas para a China, que não obedeciam às mínimas exigências que fazemos para o nosso mercado interno. 
No caso o problema aparentemente foi o de misturar sementes de soja tratadas com produtos de sanidade e destinadas ao uso como insumo, com grãos para o consumo ou uso industrial.

Ou seja, a postura dos exportadores brasileiros frente ao negócio foi rejeitada pelos importadores chineses, fazendo, assim, com que o preço sofresse drástica redução ao produtor. O impacto disso fica evidenciado no PIB do Alto Jacuí, região responsável por uma das maiores produções de soja do Rio Grande do Sul, como pode ser observado no Gráfico 1, sobretudo na relação de 2003 para 2004.

Já no que tange à seca de 2005, esta representa um agravamento da situação, pois, além do principal produto da região estar com preços baixos, a seca reduz ainda mais o valor da produção, em função, justamente, da frustração de safra ocorrida naquele ano, reduzindo, assim, ainda mais o PIB (FEE, 2014).

Essa crise evidencia, de forma conjunta com o histórico da primeira metade da década de 2000, ou, até mesmo, de forma isolada, as prováveis causas para o fluxo migratório negativo da região, como já mencionado.

Analisando-se o gráfico 1 de maneira sobreposta, PIB e população, verificase justamente que essa sofreu uma diminuição acompanhando a queda daquele. Disso depreendem-se algumas reflexões. Embora população e PIB apresentem tendência semelhante e a correlação entre ambos tenha sido estimada em um percentual bem elevado, o que Ihe dá base estatística para sustentação do argumento, não há garantias de que os mesmos efetivamente estejam associados em seus comportamentos. Mas que, os fatos vistos em conjunto com as estatísticas, são fortes evidências de que há, sim, essa conexão, fortalecendo, dessa forma, o argumento de Bandeira (2013).

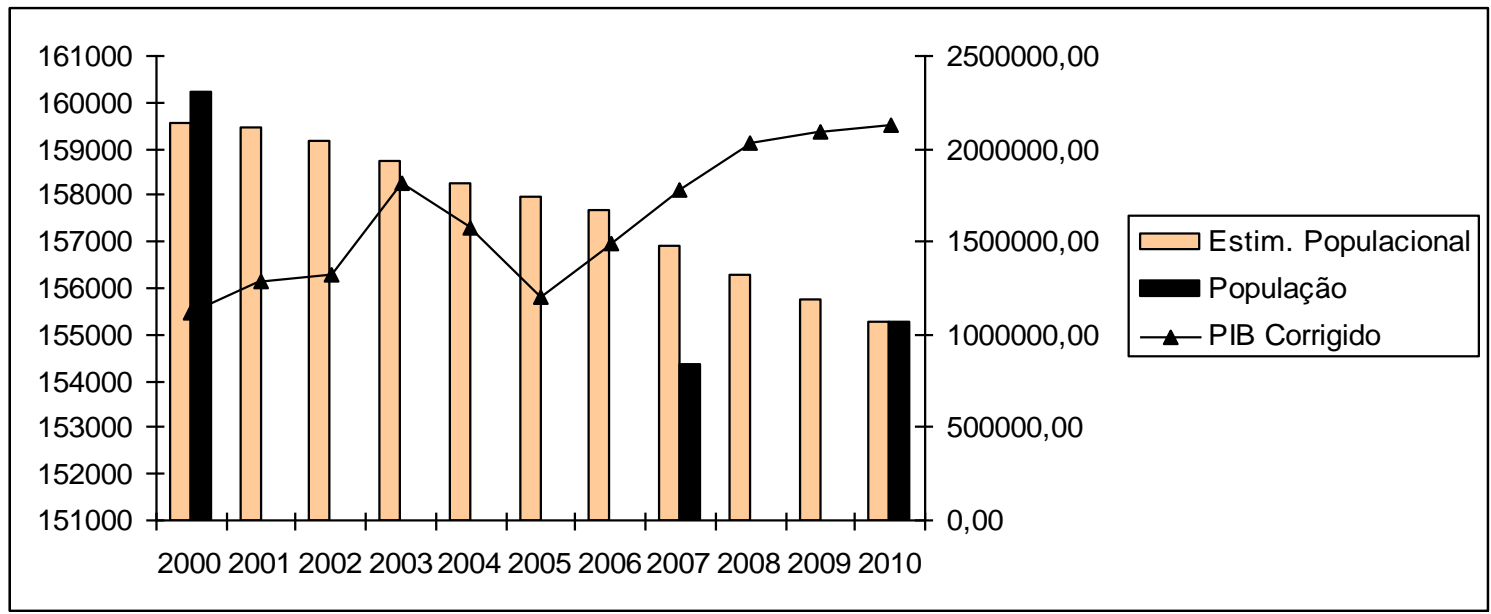

Gráfico 1: relação PIB (em mil reais) e população do Alto Jacuí entre 2000 e 2010.

Fonte: FEE, 2014.

Além da perda populacional verificada, é possível fazer uma reflexão a partir dos dados coletados no censo que refletem a migração, embora com a ressalva de que são amostras feitas a partir dos questionários censitários.

Denota-se que no recorte da segunda metade da década de 2000, residentes ininterruptamente nos municípios com até cinco anos de residência, é um número bem maior do que os migrantes da primeira metade da mesma 
década. Analisando de outra forma, mesmo que a região tenha perdido população entre os censos de 2000 e 2010, ainda assim recebeu migrantes, o que demonstra que a saída de população foi maior do que a apresentada no censo. ${ }^{14}$

Além disso, a migração é mais concentrada após os eventos de 2005, principalmente, trabalha-se com a possibilidade ou hipótese de que 2005, ano da grande seca, é um marco divisor.

Destaca-se, nesse caso, Ibirubá e Não Me Toque, que apresentam a maior taxa de crescimento da população, visto que são municípios que demonstram uma certa proporcionalidade na tendência, ou seja a migração acompanha a variação populacional. De outro lado, os demais municípios apresentam um descolamento, ou seja, embora em alguns deles haja alta recepção de migrantes há perda de população ou um crescimento menor, o que denota alta perda de população por emigração. Tais considerações podem ser melhor observadas na Tabela 2, a seguir, devendo ser lidos em conjunto com a Tabela 1.

Tabela 2. Pessoas que tinham menos de 10 anos ininterruptos de residência no município, ano 2010

\begin{tabular}{l|ccccc}
\hline \multirow{2}{*}{\multicolumn{1}{c|}{ Município }} & \multicolumn{4}{|c}{ Tempo ininterrupto de residência no município } \\
\cline { 2 - 5 } & Menos de 1 ano & 1 a 2 anos & 3 a 5 anos & 6 a 9 anos \\
\hline Boa Vista do Cadeado & 105 & 159 & 94 & 66 \\
Boa Vista do Incra & 72 & 131 & 125 & 208 \\
Colorado & 99 & 127 & 145 & 118 \\
Cruz Alta & 1.478 & 1.961 & 2.530 & 2.132 \\
Fortaleza dos Valos & 100 & 129 & 83 & 123 \\
Ibirubá & 629 & 908 & 904 & 821 \\
Lagoa dos Três Cantos & 49 & 53 & 111 & 136 \\
Não-Me-Toque & 535 & 718 & 656 & 871 \\
Quinze de Novembro & 96 & 179 & 222 & 175 \\
Saldanha Marinho & 77 & 95 & 120 & 82 \\
Salto do Jacuí & 349 & 501 & 665 & 618 \\
Santa Bárbara do Sul & 297 & 243 & 386 & 295 \\
Selbach & 172 & 265 & 258 & 184 \\
Tapera & 471 & 461 & 282 & 394 \\
\hline
\end{tabular}

Fonte: IBGE, 2014.

Embora a argumentação dos Coredes, embasada no texto de Bandeira (2013), tenha logrado êxito no contexto da PNDR, é necessário reforçar que essa é apenas uma das facetas envolvidas quando o assunto é migração. Ao mesmo tempo, a abordagem econômica, como pondera Brandt (2014), não consegue explicar completamente as razões pelas quais ocorrem os movimentos migratórios, sobretudo ao considerar a trajetória migratória de grupos sociais distintos nos territórios. Nesse sentido, Brandt (2014) observa que a migração está envolta em elementos que se articulam em torno do campo individual e das estruturas sociais e econômicas. No entanto, em estudo realizado com migrantes provenientes da Região da Campanha, Brandt (2014) observa que os fatores estruturais

\footnotetext{
${ }^{14}$ Neste caso, verifica-se uma limitação em torno das informações resultantes do censo, que mesmo sendo abrangente quando da coleta dos dados, não é suficientemente claro na explicação dos movimentos que acontecem entre os períodos censitários.
} 
influenciam na forma como estes percebem as possibilidades de retorno e visualizam o futuro da região.

Nessa perspectiva e conforme respaldado por Santos (2003), percebe-se que os fatores econômicos podem influenciar o movimento populacional, vinculando o desenvolvimento de uma região à dinâmica e organização do capital e que, por sua vez, molda a mesma de acordo com seus interesses, o que atrai ou repele população. Nesse sentido, Schneider (2008), articulando com o que já foi ponderado por Singer (1977), ${ }^{15}$ argumenta que as migrações são motivadas por aspectos socioeconômicos que se convertem em fonte e origem do processo. Ou seja, percebe-se que as questões econômicas são causas, mas também consequências dos fenômenos migratórios, sobretudo pelas questões relacionadas ao movimento do capital.

Dessa forma, não há dicotomia entre, por exemplo, o que foi ponderado por Brandt (2014) e por Bandeira (2013), pois são pontos de vista que se complementam ao visualizarem aspectos mais amplos e que envolvam a temática das migrações em contextos regionais, visto que os fenômenos migratórios devem ser tratados de forma abrangente, atendendo, além da perspectiva econômica, variáveis como a direção e os sentidos do movimento migratório.

Assim, essas são abordagens complementares, sobretudo pelas suas especificidades. Enquanto que a perspectiva econômica, mais quantitativa, explica as generalidades, por outro lado as particularidades somente serão identificadas a partir de uma nuance qualitativa, que, evidentemente, também possui limitações ao abordar o fenômeno migratório em determinadas regiões, sobretudo no que diz respeito à obtenção de dados mais individualizados, o que será mais dispendioso e, portanto, mais oneroso tanto em termos financeiros como operacionais.

Mesmo que haja tais limitações nos estudos qualitativos sobre as migrações, Cunha (2005) aponta para limitações ainda maiores no que diz respeito aos dados estatísticos ou censitários, sobretudo pelas dificuldades enfrentadas na obtenção de dados mais específicos sobre os fenômenos populacionais, tanto no intervalo de dez anos entre os censos quanto nos períodos censitários. ${ }^{16}$ Mesmo naqueles casos em que se utilizam alguns artifícios, a partir do instrumental oferecido pela estatística ou ainda, dados oferecidos pelos órgãos oficiais, como, por exemplo, as Pesquisas Nacionais por Amostragem Domiciliar-PNAD, são dados que carecem de uma relativização ou até mesmo gerados a partir de extrapolação.

Por outro lado, o viés economicista, quantitativo, permite a inferência de algumas conclusões em torno dos movimentos migratórios, retomando a questão do Corede Alto Jacuí, cujas reflexões do texto apontam para a redução da população entre um censo e outro. Pode-se deduzir igualmente que, tendo a população se mantido estável no período entre um censo e outro, isso já sugere uma certa estagnação, denotando envelhecimento da população em função de seu baixo crescimento vegetativo, no caso crescimento negativo.

\footnotetext{
${ }^{15}$ Singer (1977) argumenta que a migração é um processo que envolve grupos sociais ou até indivíduos isolados, que não são abstrações conceituais, que se deslocam em função das transformações econômicas e sociais de um determinado local.

${ }^{16} \mathrm{O}$ interstício de dez anos entre um censo e outro é um período muito longo para que se consiga fazer avaliações pormenorizadas, o que fica latente inclusive no presente estudo. E ainda, mesmo no próprio censo, por ter a aplicação dos questionários ampliados de forma amostral, também não é capaz de distinguir os meandros dos movimentos.
} 
Peixoto (2002), por esse mesmo ângulo, referindo-se a um contexto de análise enfatizando e migração internacional em Portugal, resgata o argumento econômico para explicar os fluxos migratórios nesse país, embora reconheça e afirme a complexidade do fenômeno. O autor pondera ainda que esta é uma abordagem pouco trabalhada, a relação entre o mercado de trabalho e as migrações, ${ }^{17}$ reconhecendo que não se deve simplificar a análise quando se fala de migração, pois a mesma apresenta vários tipos. Contudo, a migração associada à economia, de acordo com Peixoto (2002), sobretudo em sua variante sociológica, é uma possibilidade a ser trabalhada, pois, na visão de Peixoto (2002, p. 53) "a ideia (quase senso-comum) é que a migração ocorre sempre que se verifica um desequilíbrio de rendimentos ou emprego."

Em essência, são duas perspectivas de análise, uma individualista (não se trata de perspectiva individualista, mas centrada nos agentes), que atribui aos indivíduos as decisões migratórias, outra estruturalista, que remete aos aspectos econômicos propriamente ditos, ${ }^{18}$ de caráter coletivo (PEIXOTO, 2002).

Complementando e reforçando o raciocínio, toma-se por base o Índice de Desenvolvimento Socioeconômico ${ }^{19}$-IDESE para a região do Corede Alto Jacuí no período avaliado. Em 2004, o indicador apresentava uma magnitude de 0,769, numa escala até 1 , enquanto, para 2005 , o seu resultado foi 0,755 , fato explicado pela variável renda, que teve uma redução de 0,836 para 0,667. Em outras palavras, há coerência em se afirmar que a frustração de safra gerou uma queda na renda da região e, consequentemente, o fluxo migratório evidenciado na contagem populacional de 2007 e corroborado pelo censo de 2010. Justamente esse é o argumento utilizado por Bandeira (2013) para contrapor a adoção do critério renda per capita adotado pelo $\mathrm{MI}$, justificando, com isso, a demanda pela utilização da emigração como indicador.

Cabe salientar que o Corede Alto Jacuí, a partir do critério renda per capita, apresentou, em 2008 (último ano disponível da série), o índice de 0,887, obtido em decorrência dos preços agrícolas elevados no mercado internacional, elevando, assim, o IDESE para 0,779. Esse resultado excluiria o Alto Jacuí do conceito de região problema, conforme a proposição original da PNDR.

De forma crítica, Rolnik e Klink (2011) corroboram que o raciocínio focado na renda é enviesado, ao referenciarem como dinâmicas as regiões exportadoras, como o caso o Alto Jacuí. A consequência dessa abordagem resulta em uma nova

\footnotetext{
${ }^{17}$ Esta é a base implícita do argumento de Bandeira (2013).

${ }^{18} \mathrm{O}$ autor pondera que a variante estrutural contribui para a explicação correlacionando o conceito da divisão internacional do trabalho co a teorias dos sistemas migratórios, "os 'caminhos' colectivos para a migração são, deste modo, criados pela economia, seguindo os desequilíbrios de poder e riqueza que surgem mundialmente". (PEIXOTO, 2002, p.53) Também explorando a explicação com base na estrutura Sasaki e Assis (2000), ponderam que a análise econômica da migração trabalha não apenas considerando as clássicas tesouras das relações de mercado neoclássicas (curvas de oferta e demanda), mas também avaliando os processos responsáveis pelas transformações dos mesmos, e que a reestruturação ou reorganização da economia mundial, que afeta as economias nacionais, exercem forte influencia em tais movimentos.

${ }^{19}$ Até 2009, IDESE era um índice ponderado a partir de quatro grupos de indicadores, renda, educação saúde e saneamento, calculado pela Fundação de Economia e Estatística (FEE), em 2014 a metodologia foi alterada, com a supressão do saneamento e inclusão de novas variáveis nos grupos de indicadores. Neste caso está sendo utilizada a metodologia antiga, por conta da necessidade de explicar um cenário temporalmente a ela correlato.
} 
forma de concentração, abordado por diversos autores como a desconcentração concentrada. Esse fenômeno cria novos centros dinâmicos mais interiorizados no país, mas sem acompanhamento da melhoria das condições de vida da população, demonstrado por Rolnik e Klink (2011) ao abordarem a precariedade estrutural desses centros dinâmicos, nem sempre adequada aos rincões mais afastados do centro de poder.

Já Villaça (2000), por sua vez, pondera que resultados minimamente satisfatórios só serão obtidos se houver efetivamente o enfrentamento dos problemas, o que não se dará sem conflito, pois, se há pelo menos duas facetas nessa sociedade, a social e a empresarial, é necessário que sejam postas à mesa em discussão as duas visões, devidamente apropriadas e legitimadas para tanto.

Essa é a conexão que se coloca nessa reflexão, a reformulação da PNDR feita em forma de conferência, e, portanto, com maior e efetiva participação dos atores interessados supera a crítica por Villaça (2000), pelo menos nesse quesito, mas ainda carece de garantia de prioridade na agenda governamental. Assim, a mudança nos critérios de elegibilidade demonstra que há, na eventualidade da PNDR ser aprovada e implementada, possibilidades de inserção das regiões erroneamente consideradas dinâmicas nesse novo cenário.

\section{ALGUMAS CONCLUSÕES}

O trabalho procurou estabelecer uma discussão entre a PNDR vigente e a proposta de reformulação da mesma com vistas a transformá-la em política de Estado, para o que foi utilizada a proposição da conferência. Dessa discussão derivam os critérios adotados como objeto de reflexão que se objetivou fazer no presente texto, a saber, as aproximações existentes entre a dinâmica econômica de uma região e os movimentos migratórios.

A primeira versão da PNDR foi elaborada de forma centralizada no ambiente intraministerial e tomou como premissa básica a variável renda como principal enfrentamento com vistas a diminuir as desigualdades regionais. Já a CNDR, elaborada a partir de um enfoque mais participativo, a própria conferência denota isso, ainda está muito focada no critério renda como elegível. A partir de reflexões inspiradas em Bandeira (2013), percebe-se que os Coredes apresentaram uma proposta de revisão dos critérios com foco na migração, partindo do pressuposto de que a migração se dá a partir das oportunidades de trabalho ou não.

Com referência ao Corede Alto Jacuí, foi feita uma breve reflexão a partir dos indicadores de renda e da taxa de migração negativa no último decênio. Como base analítica, foi utilizada a ponderação de que os modelos econômicos não são capazes de explicar por si só as causas e motivações dos fluxos migratórios. No que tange aos aspectos mais genéricos em análise, a ciência econômica consegue apresentar um conjunto de argumentos que podem explicar o movimento como tendência, sobretudo correlacionando o desempenho da economia regional com os fluxos migratórios. Nesse sentido, buscou-se abordar o fenômeno migratório na região como resultado de experiência de articulação entre o campo individual e o estrutural ao elucidar, por exemplo, que determinados acontecimentos específicos 
podem ser igualmente relevantes para compreender as causas e consequências do processo migratório regional.

Como fruto da reflexão proposta, apresenta-se um olhar em torno de certos entraves da PNDR, tanto em sua primeira versão ou até mesmo em sua reformulação, carecendo estas de um maior aprofundamento sobre questões que sejam pertinentes para muitas regiões, entre elas, o fenômeno migratório. Cabe, no entanto, ressaltar que tal fenômeno seja considerando, inclusive, a partir de outras fontes de dados, bem como de aprofundamentos teóricos, confrontando informações regionais com vertentes teóricas que, dialeticamente, abordem a essência e complexidade do tema para discutir proposições políticas efetivas voltadas para o desenvolvimento regional.

\section{REFERÊNCIAS}

AGRIANUAL, 2010. Anuário da agricultura brasileira. São Paulo: AgraFNP, 2010.

BANDEIRA, Pedro Silveira. Contribuição dos Coredes/RS para o debate sobre a Política Nacional de Desenvolvimento Regional. In: RANDOLPH, Rainer; TAVARES, Hermes M. (org.). Política e planejamento regional: uma coletânea. Brasília: UP Gráfica, 2013.

BRANDT, GRAZIELLE. Migração e Território: olhares de um grupo de migrantes sobre a região da Campanha. REDES - Rev. Des. Regional, Santa Cruz do Sul, v. 19, ed. especial, p. 79-92, 2014.

CUNHA, José Marcos Pinto. Migração e urbanização no Brasil: alguns desafios metodológicos para análise. São Paulo em Perspectiva, v. 19, n.4, p.3-20; out/dez 2005. Disponível em:

<http://www.scielo.br/scielo.php?script=sci_arttext\&pid=S0102-

$88392005000400001>$. Acesso em 30 set 2014

FEE. Carta de Conjuntura FEE. (vários números). Porto Alegre: FEE, 2014. disponível em <http://fee.rs.gov.br>. Acesso em 15 set 2014.

FEE. Índice de Desenvolvimento Econômico do RS (IDESE): 2001-2009. Porto Alegre: FEE, 2011. disponível em <http://fee.rs.gov.br>. Acesso em 15 jun 2012.

FEE. Índice de Desenvolvimento Econômico do RS (IDESE): 2007-2010. Porto Alegre: FEE, 2014. disponível em <http://carta.fee.tche.br/numeros-anteriores/>. Acesso em 15 set 2014.

MINISTÉRIO DA INTEGRAÇÃO NACIONAL. Secretaria de Políticas de Desenvolvimento Regional. Instituto Interamericano de Cooperação para a Agricultura - IICA. Política Nacional de Desenvolvimento Regional- PNDR (sumário executivo). Brasília, 2003. 
MINISTÉRIO DA INTEGRAÇÃO NACIONAL. Secretaria de Desenvolvimento Regional. A PNDR em dois tempos: a experiência apreendida e o olhar pós 2010. Brasília, DF: 2010. Disponível em:

$<$ http://www.integracao.gov.br/desenvolvimentoregional/pndr2/>. Acesso em 12 mar 2012.

MINISTÉRIO DA INTEGRAÇÃO NACIONAL. Secretaria de Desenvolvimento Regional. Conferência Nacional de Desenvolvimento Regional: (documento de referência). Brasília, julho de 2012.

MINISTÉRIO DA INTEGRAÇÃO NACIONAL. Secretaria de Desenvolvimento Regional. Conferência Nacional de Desenvolvimento Regional.(resumo executivo). Brasília, julho de 2012.

PEIXOTO, João Alfredo. Migrações internacionais e globalização: mobilidade, mercado de trabalho e relações sociais. In: SCHERER-WARREN, Ilse; FERREIRA, José Maria Carvalho. Transformações sociais e dilemas da globalização: um diálogo Brasil/Portugal. São Paulo: Cortez, 2002.

ROLNIK, Raquel; KLINK, Jeroen. Crescimento econômico e desenvolvimento urbano: por que nossas cidades continuam tão precárias? In: Novos Estudos Cebrap, n/ 89, Março, 2011. Disponível em: <http://www.scielo.br/pdf/nec/n89/06.pdf> Acesso em 10 out 2014.

SANTOS, M. Economia espacial: críticas e alternativas. São Paulo: Hucitec, 2003.

SASAKI, Elisa Massae; ASSIS, Gláucia de Oliveira. Teorias das migrações internacionais. In: XII Encontro Nacional da Abep. Anais... Caxambu, outubro de 2000. Disponível em:

http://www.abep.nepo.unicamp.br/docs/anais/pdf/2000/Todos/migt16_2.pdf.Ac esso em 30 mar 2015.

SINGER, P. Economia política da urbanização. São Paulo: Contexto, 2002.

SCHNEIDER, lara Elisa. Movimentos migratórios no contexto de abertura $e$ fechamento das fronteiras agrícolas. Programa de Pós-Graduação Strictu Sensu em Desenvolvimento Regional e Agronegócio. Universidade Estadual do Oeste do Paraná - UNIOESTE, TOLEDO - PR, 2008. Dissertação

VILLAÇA, Flavio. Perspectivas do planejamento urbano no Brasil de hoje. Campo Grande, Junho, 2000. p.1-16. Disponível em: <http://www.flaviovillaca.arq.br/pdf/campo_gde.pdf> Acesso em 10 out 2014.

ZYLBERSTAJN, Decio. Barrados na China: lições para a cadeia da soja. In: NEVES, Marcos Fava; ZYLBERSTAJN, Decio; NEVES, Evaristo Marzabal. Agronegócio do Brasil. São Paulo: Saraiva, 2005. 
Submetido em 21/07/2014

Aprovado em 20/10/2015

Sobre os autores

José Carlos Severo Corrêa

Mestre em Desenvolvimento Regional - Universidade de Santa Cruz do Sul. Doutorando em Desenvolvimento Regional - Universidade de Santa Cruz do Sul. Professor assistente da Universidade Federal do Pampa.

Endereço: Rua Luiz Joaquim de Sá Britto, Bairro Promorar - 97650000 - Itaqui, RS - Brasil.

E-mail: josecorrea@unipampa.edu.br

\section{Rogério Leandro Lima da Silveira}

Mestre e Doutor em Geografia Humana pela Universidade Federal de Santa Catarina. PósDoutorado em Geografia e Planeamento Regional pela Universidade Nova de Lisboa. Professor titular e pesquisador do Departamento de História e Geografia, e pesquisador e orientador no Programa de Pós-Graduação em Desenvolvimento Regional - Mestrado e Doutorado, da Universidade de Santa Cruz do Sul.

Endereço: Av. Independência, 2293, Bairro Universitário - 96815-910 - Santa Cruz do Sul, RS Brasil.

E-mail: rlls@unisc.br

\section{Grazielle Betina Brandt}

Doutora em Desenvolvimento Regional pela Université du Quebéc à Rimouski - UQAR (2010). Professora do e pesquisadora do Departamento de Comunicação Social e do Programa de PósGraduação em Desenvolvimento Regional da Universidade de Santa Cruz do Sul.

Endereço: Av. Independência, 2293, Bairro Universitário - 96815-910 - Santa Cruz do Sul, RS Brasil.

E-mail: grazielle@unisc.br 